(final draft - to appear in Science \& Education)

\title{
Why machine-information metaphors are bad for science and science education
}

Abstract. Genes are often described by biologists using metaphors derived from computational science: they are thought of as carriers of information, as being the equivalent of "blueprints" for the construction of organisms. Likewise, cells are often characterized as "factories" and organisms themselves become analogous to machines. Accordingly, when the human genome project was initially announced, the promise was that we would soon know how a human being is made, just as we know how to make airplanes and buildings. Importantly, modern proponents of Intelligent Design, the latest version of creationism, have exploited biologists' use of the language of information and blueprints to make their spurious case, based on pseudoscientific concepts such as "irreducible complexity" and on flawed analogies between living cells and mechanical factories. However, the living organism = machine analogy was criticized already by David Hume in his Dialogues Concerning Natural Religion. In line with Hume's criticism, over the past several years a more nuanced and accurate understanding of what genes are and how they operate has emerged, ironically in part from the work of computational scientists who take biology, and in particular developmental biology, more seriously than some biologists seem to do. In this article we connect Hume's original criticism of the living organism = machine analogy with the modern ID movement, and illustrate how the use of misleading and outdated metaphors in science can play into the hands of pseudoscientists. Thus, we argue that dropping the blueprint and similar metaphors will improve both the science of biology and its understanding by the general public.

Keywords: genes as blueprints, machine metaphor, intelligent design, developmental encoding, science education, pseudoscience 
"To the few this is as clear as daylight, and beautifully suggestive, but to many it is evidently a stumbling-block."

(Alfred Russel Wallace to Charles Darwin, on the use of the metaphor of natural selection)

"The price of metaphor is eternal vigilance."

(A. Rosenblueth and N. Wiener, cited in Robert Root-Bernstein's "Metaphorical Thinking," American Scientist Nov/Dec 2003)

Introduction: the machine metaphor in biological science and education

Scientific thinking and education are rife with the use of metaphors. Well-known examples including physics (heavy objects on a blanket as an image of space-time curvature), chemistry (atoms as miniature solar systems), ecology (the planet Earth as a homeostatic organism), and many others (Condit et al. 2002; Brown 2003). In biology and biological education in particular, metaphors are pervasive at almost every level of description and explanation. Brown (2003, p. 159) has even argued that "biology today reveals more forcefully than any other area of science the essential role of metaphor on scientific reasoning and communication." Perhaps this pervasiveness of metaphors is an inevitable result of the way human beings think (Lakoff \& Johnson 1980; De Cruz \& De Smedt 2010), but it has consequences for both science education and scientific research, and not necessarily for the better. For instance, Fox Keller (1995) made that case concerning information-type metaphors in the broad field of genetics (see also Nelkin 2001), while Martin (1994) has done the same for the more specific area of immunology and HIV-AIDS research.

The simple empirical observation that science talk depends heavily on analogical thinking mandates that we examine the consequences of deploying certain metaphors on how students and the public at large end up understanding science, and that we be attentive to the way pseudoscientists often seize upon these metaphors to foster misunderstandings. Specifically, if we want to keep Intelligent Design out of the classroom, not only do we have to exclude the 'theory' from the biology curriculum, but we also have to be weary of using scientific metaphors that bolster design-like misconceptions about living systems. 
We argue that the machine-information metaphor in biology not only misleads students and the public at large, but cannot but direct even the thinking of the scientists involved, and therefore affect the sort of questions they decide to pursue and how they approach them. For instance, there undoubtedly were very good reasons to pursue the Human Genome Project during the 1990s and the early part of the 21st century, but obtaining the "blueprint" for how human beings are made (and therefore cure genetic-based diseases like cancer) was certainly not one of those good reasons. Yet, it was the blueprint rhetoric — based on the actual informatics-directed thinking of the scientists involved — that helped sell the 4.2 billion effort (in 2009 dollars) to the American public, ${ }^{(1)}$ not to mention redirect the research time and intellectual efforts of tens of thousands of scientists and graduate students the world over.

Similarly, the never ending debate in science education between creationists and evolutionary biologists hinges on the persistent (mis-)understanding of biological organisms as "machines," an understanding that is perpetuated by biologists themselves in textbooks and lectures. The organism-as-machine metaphor goes much further back in time than the decidedly modern genome-as-blueprint one, to René Descartes and other mechanistic philosophers. Interestingly, as we shall see, attempts to point out its misleading effects are also quite old, beginning with David Hume's devastating critique of the idea of intelligent design.

In this paper we discuss the effect of what we call the machine-information metaphor (or family of metaphors, to be more precise) in the areas of science education and scientific research. In the first case, we examine the 'debate' about Intelligent Design and argue that some defenders of evolution themselves (unwittingly) keep fueling the widespread misunderstanding among the general public, because they accept the fundamental soundness of their opponents' characterization of organisms as machine-like. In the second case, we argue that thinking of genomes as blueprints has not only led the general public astray but may have also delayed the incorporation of developmental biology into evolutionary theory, and is still delaying the expansion of the general concept of heritable information to phenomena that rightly should fall within its purview, like epigenetic, behavioral, cultural and even environmental transgenerational effects. We conclude with a brief look at a few alternative metaphors and suggest that biological research and teaching could and should actually be done without much use of metaphorical thinking, although the widespread tendency to employ the latter may be used as a critical 
thinking tool in both general and graduate level education to produce more science-savvy citizens and scientists.

Machine metaphors, Intelligent Design and science education

When delving into unknown territory, scientists have often naturally relied on their experiences in more familiar domains to make sense of what they encounter (De Cruz \& De Smedt 2010). In the early days of the scientific revolution, mechanical metaphors proved to be a powerful instrument to get a grip on new discoveries about the living world and the universe at large. According to Niall Shanks, we can trace back the emergence of machine metaphors at least to the Middle Ages, when new achievements of technology had a profound cultural influence and captured the collective imagination (Shanks 2004, pp. 25-7). Against this background of technological innovation, it is not surprising that the pioneers of anatomy and physiology relied on the metaphor of the animal body as a complicated piece of machinery to make sense of their discoveries. The mechanical language provided a richness of meaning and allowed them to structure the new phenomena in terms of familiar experiences (Lakoff \& Johnson 1980). For example, the image of the human heart as a pump with intricate mechanical components played an important role in William Harvey's discoveries about blood circulation.

In the course of the 17th century, a new philosophy of nature became prominent that developed a conception of the universe in purely mechanical terms. According to this mechanical philosophy, which was developed by thinkers like René Descartes, Pierre Gassendi and Robert Boyle, the phenomena of nature can be understood purely in terms of mechanical interactions of inert matter (Ashworth 2003). This mechanization of nature proved an important driving force behind the Scientific Revolution, and at the end of the 17th century culminated in Newton's theory of motion. Newton's description of planetary orbits following the fixed laws of gravity conveyed an image of a clockwork universe set in motion by an intelligent First Cause. In fact, that was exactly how Newton conceived the universe and its relation to the Creator. For Newton and many of his contemporaries, the importance of the mechanical conception of nature was greater than the mere term 'metaphor' would suggest, as the development of mechanistic philosophy was itself largely inspired by religious motivations (Ashworth 2003). As Shanks wrote in his account of the history of the design argument, "the very employment of machine metaphors invited theological speculation" (Shanks 2004, p. 32). 
In the second part of the $17^{\text {th }}$ century, the mechanical pictures of living organisms and of the cosmos at large converged into an intellectual tradition where theology and science were intimately intertwined: natural theology. The most famous representative of this tradition was William Paley, whose work Natural Theology, of Evidence of Existence and Attributes of the Deity, Collected from the Appearances of Nature (1802) made a deep impression on the young Charles Darwin. As the title of the book makes clear, Paley and the natural theologians conceived of Nature as a complicated machinery of intricate wheels within wheels, in which every organism has its proper place and is adapted to its environment. According to Paley, the contrivance and usefulness of parts exhibited by living organisms attests to the intelligence and providence of a benevolent Creator. This so-called 'design argument' already had a long intellectual pedigree, dating back to Plato, Cicero and Thomas Aquinas, but its most famous formulation is found in the first chapter of Natural Theology, in which Paley relies on the analogy between living organisms and a pocket watch to support his design inference. ${ }^{(2)}$

In crossing a heath, suppose I pitched my foot against a stone, and were asked how the stone came to be there: I might possibly answer, that for any thing I know to the contrary, it had lain there for ever: nor would it perhaps be very easy to show the absurdity of this answer. But suppose I had found a watch upon the ground, and it should be inquired how the watch happened to be in that place; I should hardly think of the answer which I had before given, that for any thing I knew, the watch might have always been there. Yet why should not this answer serve for the watch, as well as for the stone? Why is it not as admissible in the second case as in the first? For this reason, and for no other, viz., that when we come to inspect the watch, we perceive (what we could not discover in the stone) that its several parts are framed and put together for a purpose ... This mechanism being observed . . . the inference, we think, is inevitable, that the watch must have had a maker; that there must have existed, at some time, and at some place of other, an artificer or artificers, who formed it for the purpose which we find it actually to answer; who comprehended its construction, and designed its use. (Paley 1802, p. 5)

The idea is that without having witnessed the creation of the watch, without even knowing anything about the identity of the designer, the purposeful arrangement of parts forces the conclusion of intelligent design on the observer. Of course, there is at least one fundamental dissimilarity: human artefacts don't propagate, whereas living organisms do. However, Paley did not think this significantly endangers the analogy. Instead, he argued that it actually strengthens the design inference for the case of living organisms. After all, continues Paley, suppose that the watch we found in the heath did not only indicate the time, but was also capable of producing 
another watch with the same features. Wouldn't this even more "increase [our] admiration of contrivance"? (Paley 1802, p. 9) Living organisms, according to Paley, surpass the ingenuity and complexity of human artefacts "in a degree which exceeds all computation" (Paley 1802, p. 13), and are worthy of a divine Creator alone. Even Kant, in his Critique of Judgment, clearly struggled with the apparently purposeful design of living organisms. Although he was wary of teleological accounts, always preferring "efficient" mechanical causes for explaining the world, he acknowledged that living systems necessarily had to be explained "as if" they were teleological in nature. Thus, he maintained that "it is absurd to hope that another Newton will arise in the future who shall make comprehensible by us the production of a blade of grass according to natural laws which no design has ordered" (Kant 2007, 185). It seems that for beings such as ourselves, used to associate complexity with intelligence, it is very difficult to escape the impression of design in nature, and the adaptive complexity of living organisms certainly demands a special explanation. Darwin's theory of evolution by natural selection eventually provided such explanations, fatally undermining Paley's argument, and flagrantly contradicting Kant's pessimism on the matter.

While Darwin was the one who gave the most decisive blow to the design argument by suggesting a natural explanation for adaptive complexity in the living world, many philosophers would agree that David Hume foreshadowed its demise, by exposing several problems with the central analogy. In his work Dialogues Concerning Natural Religion (Hume 1779), which actually predates Paley's magnum opus by more than 50 years, we find a discussion of the design argument among Philo, the skeptical character that voices Hume's ideas, Demea, the orthodox religious believer, and Cleanthes, the advocate of natural theology.

After Cleanthes has set out the design argument in terms foreshadowing Paley's analogy of the watch, Philo objects that it is dangerous to derive conclusions about the whole of the universe on the basis of a spurious analogy with one of its parts. Given that our experience with design is limited to human artifacts only, we have to proceed with great caution, and it would be presumptuous to take so minute and select a principle as the human mind as the model for the origin of the whole universe. ${ }^{(3)}$ Hume realized that, at least in some cases, appearances of intelligent design can be deceptive. In the words of Philo:

If we survey a ship, what an exalted idea must we form of the ingenuity of the carpenter who framed so complicated, useful, and beautiful a machine? And what surprise must we feel, when we find him a stupid mechanic, who imitated others, and copied an art, which, through a long succession of ages, 
after multiplied trials, mistakes, corrections, deliberations, and controversies, had been gradually improving? (Hume 1998 [1779], p. 36)

In contemplating that " $[\mathrm{m}]$ any worlds might have been botched and bungled, throughout an eternity, ere this system was struck out", Hume even comes close to Darwin's crucial insight about the power of natural selection. (Ibid, p. 36)

Although Hume does not deny that we can discern similarities between nature and human artifacts, he warns us that the analogy is also defective in several respects. And if the effects are not sufficiently similar, conclusions about similar causes are premature. To illustrate this, Philo proposes another possible cosmogony on the basis of the analogy between the world and an animal:

A continual circulation of matter in [the universe] produces no disorder; a continual waste in every part is incessantly repaired: The closest sympathy is perceived throughout the entire system: And each part or member, in performing its proper offices, operates both to its own preservation and to that of the whole. The world, therefore, I infer, is an animal. (Hume 1998 [1779], p. 39)

Philo further speculates that the world even more resembles a plant, and that it could have come into existence by a process analogous to reproduction or vegetation. While the others protest at his arbitrary speculations, Philo maintains that his analogies, though certainly defective in some respects, are no more so than the machine analogy. "[I]n such questions as the present, a hundred contradictory views may preserve a kind of imperfect analogy, and invention has here the full scope to exert itself" (Hume 1998 [1779], p. 49). Aware of the fallibility and imperfections of human reasoning, Hume remains highly skeptical about the design inference and the machine analogy, even though he was not able to provide a satisfactory explanation for the appearance of design in nature.

In the Origin of Species, Charles Darwin (1859) finally proposed a natural explanation for the phenomenon that inspired Paley but failed to convince Hume. Although the design argument is still of interest to philosophers and historians of science, it has been widely discarded in the scientific community. However, the analogy on which Paley based his inference seems to be alive and well, not only in the minds of creationists and ID proponents, but also in the writings of science popularizers and educators (and even in actual scientific work, as we will see in the next section). Many scientists have actually argued that Paley at least offered an incisive formulation of the problem as there is indeed a hard-to-shake intuition of contrivance 
and intelligent design in nature. As one of the most ardent defenders and popularizers of evolutionary theory put it, "Biology is the study of complicated things that give the appearance of having been designed for a purpose" (Dawkins 1991, p. 1). Adaptive complexity, then, is still regarded as something that requires a special explanation.

In textbooks, science educators have presented the comparison of living organisms and man-made machines not just as a superficial analogy, but carrying it out to a considerable level of detail. For example, the cell has been described as a miniature factory, complete with assembly lines, messengers, transport vehicles, etc. Consider the following quote from Bruce Alberts, former president of the National Academy of Sciences:

The entire cell can be viewed as a factory that contains an elaborate network of interlocking assembly lines, each of which is composed of a set of large protein machines. ... Why do we call the large protein assemblies that underlie cell function protein machines? Precisely because, like machines invented by humans to deal efficiently with the macroscopic world, these protein assemblies contain highly coordinated moving parts. Given the ubiquity of protein machines in biology, we should be seriously attempting a comparative analysis of all of the known machines, with the aim of classifying them into types and deriving some general principles for future analyses. Some of the methodologies that have been derived by the engineers who analyze the machines of our common experience are likely to be relevant. (Alberts 1998, p. 291)

Similarly, in their popular high school textbook Biology, Kenneth Miller and Joe Levine develop an extensive analogy between the living cell and a manufacturing plant (Levine and Miller 1994). In Miller's own words:

The nucleus is the factory's main office, the mitochondria its power plants, the ribosomes its manufacturing equipment, and the Golgi apparatus its shipping and receiving department. (Miller 2008, p. 27)

In line with the machine metaphor, scientists have also conceived of the genome as a 'blueprint' for the organism, written in a four-letter alphabet and in a language that scientists have deciphered. In the wake of the Humane Genome Project, many scientists have enthusiastically described the human DNA sequence as "the book of life" or "the blueprint for a human being" (for an overview, see Nelkin, 2001). In an interview for Time about the Human Genome Project, biochemist Robert Sinsheimer has described the genome as "the complete set of instructions for making a human being [...] written in the language of deoxyribonucleic acid, the fabled DNA molecule" (Jaroff 1989). According to Miller, machine metaphors are useful because they allow 
teachers to get across complicated material, since they are "easy to remember and make scientific sense" (Miller, 2008, p. 27). However, we will see that analogies between living organisms and machines or programs (what we call "machine-information metaphors") are in fact highly misleading in several respects. Bearing in mind that metaphors are powerful persuasive tools that can deeply affect the way we look at the world, we think the pervasiveness of extensive machine analogies in science education is in fact unfortunate.

Creationists and their modern heirs of the Intelligent Design movement have been eager to exploit mechanical metaphors for their own purposes (Perakh, 2008). For example, Bruce Alberts' description of the living cell as a factory has been approvingly quoted by both Michael Behe and William Dembski, two leading figures in the ID movement. For ID proponents, of course, these are not metaphors at all, but literal descriptions of the living world, arching back to Newton's conception of the Universe as a clock-like device made by the Creator. The very fact that scientists rely on mechanical analogies to make sense of living systems, while disclaiming any literal interpretation, strengthens creationists in their misconception that scientists are 'blinded' by a naturalistic prejudice. And of course, the idea of a genomic 'blueprint' is highly congenial to the theistic worldview ${ }^{(4)}$ of ID proponents. In the creationist textbook Of Pandas and People, which has been proposed by ID advocates as an alternative to standard biology textbooks in high school, we read that "Intelligent design [...] locates the origin of new organisms in an immaterial cause: in a blueprint, a plan, a pattern, devised by an intelligent agent" (Davis et al., 1993, p. 14). ${ }^{(5)}$

The analogy between living organisms and man-made machines has proven a persuasive rhetorical tool of the ID movement (for a thorough examination of ID theory, see Pennock, 1999; Shanks 2004; Pigliucci 2002). In fact, for all the technical lingo and mathematical 'demonstrations,' in much of their public presentations it is clear that ID theorists actually expect the analogies to do the argumentative work for them (Young, 2004). In Darwin's Black Box, Behe takes Alberts' machine analogy to its extreme, describing the living cell as a complicated factory containing cargo-delivery systems, scanner machines, transportation systems and a library full of blueprints. Here is a typical instance of Behe's reasoning:

In the main area [cytoplasm] are many machines and machine parts; nuts, bolts, and wires float freely about. In this section reside many copies of what are called master machines [ribosomes], whose job it is to make other machines. They do this by reading the punch holes in a blueprint 
[DNA], grabbing nuts, bolts, and other parts that are floating by, and mechanically assembling the machine piece by piece. (Behe, 2006, pp. 104-5)

Behe's favorite model of biochemical systems is a mechanical mousetrap, the familiar variant consisting of a wooden platform, a metal hammer, a spring etc. According to Behe, if any one of these components is missing, the mousetrap is no longer able to catch mice. He has termed this interlocking of parts "irreducible complexity" and thinks it characterizes typical biochemical systems. As Shanks wrote: "[t]he mousetrap is to Behe what the well-designed pocket watch was for Paley" (Shanks, 2004, p. 165). But whereas Paley can be excused on the grounds of the state of scientific knowledge in the $18^{\text {th }}$ century, for Behe the situation is a little different. Modern biochemistry, nota bene Behe's own discipline, has revealed that biochemical systems are not like mechanical artifacts at all (see our discussion of "brittleness" below; see also Shanks and Joplin 1999). Moreover, even biological systems that are irreducibly complex under Behe's definition pose no problem for evolution by natural selection, see for example Miller (2000).

ID proponents have buttressed their analogies between living systems and mechanical contraptions with a lot of visual rhetoric as well. The flagellum of the bacterium E. coli, the hallmark of the ID movement, has been represented as a full-fledged outboard rotary motor, with a stator, drive shaft, fuel supply etc. It features on the cover of Dembski's book No Free Lunch and has been used numerous times in presentations and online articles. The idea seems to be that if it looks designed, it has to be designed. But as Mark Perakh has documented, ID supporters invariably use idealized and heavily stylized representations of the flagellum, in order to make it more resemble a man-made contraption (Perakh, 2008). Another striking example of this visual rhetoric is a new video by Discovery Institute president Stephen C. Meyer, ${ }^{(6)}$ which presents a computer-simulated - and again heavily stylized - journey inside the cell, and describes the biochemical processes in terms of "digital characters in a machine code," "informationrecognition devices" and "mechanical assembly lines." Meyer commented that evolutionists will have a hard time now dissuading the public from the fact that "the evidence for design literally unfolds before them."

Of course, the mere observation that creationists have seized on machine metaphors in biology does not suffice to demonstrate that these metaphors do not make scientific sense. However, the fact that they tend to do so systematically, using full-length quotes from respectable scientists, should make us weary of the possible dangers of misleading metaphors. If the rhetoric of the ID movement is demonstrably based on these mechanical analogies, it can be 
instructive to reexamine their scientific merits. In the next section, we argue that the machineinformation analogy has indeed influenced the way scientists themselves think about biological structure, function, and evolution. By analyzing the consequences of and reactions to this analogy in actual biological research, we show that its scientific merits are very week indeed, and that its place in modern biology has become questionable.

Machine metaphors and the practice of biological research

The idea of the organism as a machine, a device that stores and acts on information, has permeated not just education about biological science, but the practice of that science itself. Descartes (1648) in L'Homme developed the fundamental idea that living organisms, including human beings (but in the latter only as far as the "vegetative" aspects of the body are concerned) are machines, whose function can be understood in terms of simple mechanical forces and interactions. This was part of Descartes' overall program of countering Aristotelian science and developing a new physics based on the "mechanical philosophy" that was inspiring Galilei and later found full fruition in Newton, giving birth to what we recognize as modern science. Biology, however, has always also been characterized by the presence of an anti-reductionist, vitalistic streak, which ironically periodically arches back to Aristotle (350BE/1991) and his conception of vegetable and animal "souls" as presented in his De Anima.

This back and forth between mechanistic and vitalistic conceptions of living organisms characterized debates among biologists during the 19th century, when Darwin's ideas can be seen as certainly more mechanistic in nature than, say, those of Lamarck. The vitalistic position gained new prominence again at the beginning of the 20th century, largely through the efforts of Henri-Louis Bergson, but evolutionary biology kept moving steadily in a mechanistic direction throughout the Modern Synthesis of the 1930s-40s (Mayr and Provine 1998). The coup de grace was then given to vitalism by the onset of the molecular revolution, first anticipated in Schrödinger's What is Life? (1944) and then definitely playing a determinant role in late 20th century biology after the discovery of the structure of DNA (Watson and Crick 1953).

Ever since the 1950s what we might more properly call the machine-information metaphor has been prevalent in molecular biology and, by extension because of the tremendous success of the molecular revolution, throughout the biological sciences (despite continued pockets of resistance within the more organismally oriented disciplines of biology, chiefly 
ecology and evolutionary biology). It is sometimes argued by biologists that the use of machineinformation metaphors is limited to popular writings of the type discussed in the previous section, and that they do not inform actual research papers. But this is quickly dispelled by an even cursory examination of databases such as Web of Science or PubMed.

Let us take, for instance, the idea that genes are "blueprints," i.e. that they contain the information to build proteins or more broadly any aspect of the phenotype. Hassoun et al. (2009) talk about "differentiation of the principal body axes in the early vertebrate embryo [being] based on a specific blueprint of gene expression" and say that the "mouse and rabbit show distinct structural differences in APD [anterior pregastrulation differentiation] and the[ir] molecular blueprint." Iimura et al. (2009) refer to "the colinear disposition of Hox genes expression domains [which] provides a blueprint for the regionalization of the future vertebral territories of the spine" in vertebrates. Uttamchandani et al. (2009) are confident that the sequencing of the human genomes "provided a wealth of information about the genomic blueprint of a cell" (though they do acknowledge that this does not provide "the entire story" of life and living processes). Rutka et al. (2009) affirm that "the human genome project has been completed providing a blueprint for the human species." Saminathan et al. (2009) maintain that their "neuronal transcripts were further analyzed to provide a genetic blueprint that can be used by neurobiologists to unravel the complex cellular and molecular mechanisms underlying biological functions." And the list could easily be extended to encyclopedic proportions.

One of the obvious patterns emerging from any such search of the recent literature is that words like "blueprint" are rarely if ever used within the context of organismal (as opposed to molecular) biological research, and indeed there is a sustained effort on the part of (some) ecologists and evolutionary biologists to counter what they see as the hyper-reductionist approach brought about by the molecular revolution. This is particularly evident when we focus on ongoing discussions on the scope and results of "evo-devo" (evolution of development), the relatively new field that is supposed precisely to bridge the gap between organismal and molecular biology, all the while finally bringing developmental biology into the broad fold of the standard theory of evolution known as the Modern Synthesis (e.g., Minelli and Fusco 2005; Love 2006; Hendrikse et al. 2007; Müller 2007; Pigliucci 2009). This resistance against the machine-information metaphor, however, cannot and should not be read as a resurgence of vitalism, as no evo-devo author has moved in that direction. Rather, it is the result of a genuine tension between the undeniable successes of the molecular-reductionist approach on the one 
hand, and the limits that such approach seems to reach when it tackles issues pertinent to the structure and evolution of complex phenotypes.

We argue that part of this tension is in fact the result of, or is at least fostered by, the deployment of the machine-information metaphor as a guiding idea of the molecular biological research program (see the sample of recent references provided above), and that new ways of thinking about development and evolution are building a conceptual vocabulary that increasingly distances itself from the machine-information metaphor. Let us consider two broad categories of examples, what we will be referring to as "the problem of development" and "the problem of environment."

The problem of development has arguably been present in one form or another throughout the history of biology, and in modern shape constitutes the central aim of the research program in evo-devo. If living organisms are sufficiently analogous to programmable machines, then the problem of development largely reduces to identifying which pieces of the "program" (i.e., genes) "control" which parts of the hardware to be assembled (the organism itself). That this is a line of inquiry actually pursued by biologists over the past few decades — and not just a matter of idle talk — is evident from the bewildering literature on "genes for" a particular phenotype, even though the very notion of a gene being "for" a phenotype is in fact justified only in very restricted cases (Kaplan and Pigliucci 2001). While it can certainly be argued that the approach has been successful, in reality that success is largely limited to one of two areas: the identification of few complex phenotypic traits that do show a relatively simple "mapping" between genotype and phenotype (e.g., eye color in vertebrates, see Sturm and Larsson 2009), or the cataloguing of large numbers of genes affecting a given phenotype (often, in the case of humans, a disease-related one), where however each genetic element statistically accounts for a minute fraction of the variation in the phenotype, and often only in a particular subset of populations within a given species (Tian et al. 2008; Wu and Zhao 2009).

Recent advancements in theoretical biology and computational science may help us to articulate the fundamental reasons why the problem of development cannot be solved by more and better Genotype ${ }^{\circledR}$ Phenotype mapping. Ciliberti et al. (2007) have pointed out that direct encoding systems , such as human-designed software, suffer from brittleness , that is they break down if one or a few components stop working, as a result of the direct mapping of instructions to outcomes. If we think of living organisms as based on genetic encoding systems — like blueprints - we should also expect brittleness at the phenotypic level which, despite the 
claims of creationists and ID supporters that we have encountered above, is simply not observed. On the contrary, biological developmental systems tend to be very robust to both internal (i.e., genetic) and external (i.e. environmental) perturbations. In other words, pace Behe and other ID advocates, removing one component in a complex biochemical pathway typically does not cause the system to "effectively cease functioning" (Behe 2006, p. 39). Indeed, the fact that biological organisms cannot possibly develop through a type of direct encoding of information is demonstrated by calculations showing that the gap between direct genetic information (about 30,000 protein-coding genes in the human genome) and the information required to specify the spatial position and type of each cell in the body is of several orders of magnitude (Stanley 2007). Where does the difference come from?

An answer that is being explored successfully is the idea that the information that makes development possible is localized and sensitive (as well as reactive) to the conditions of the immediate surroundings. In other words, there is no blueprint for the organism, but rather each cell deploys genetic (Johannes et al. 2008) information and adjusts its status to signals coming from the surrounding cellular environment, as well as from the environment external to the organism itself. The way this works, then, is through two phases: in the signaling phase information is deployed locally, within a given circuit (in computational science models) or cell (in biological systems). The second phase is that of the expression of a particular functional status, which depends on the input received so far by each circuit or cell. In computational science, interestingly enough, this approach is known as "developmental encoding" or "artificial development" and is in fact inspired by a more realistic view of what sort of systems living organisms actually are (Hartmann et al. 2007).

One of the most interesting outcomes of shifting our thinking from direct/genetic encoding to indirect/developmental encoding of information is that we then have an immediate link between developmental biology and evolution: not only is research on localized encoding showing it to be a better model for understanding development, but it turns out that artificial systems based on developmental encoding are much more efficient at searching for more robust solutions to whatever problem is posed to them, i.e. they evolve faster than genetic encoding systems and produce phenotypes that are fault-tolerant — to use software engineering terminology — because they are not brittle (Hartmann et al. 2007): giving up talk of blueprints and computer programs immediately purchases an understanding of why living organisms are not, in fact, irreducibly complex. 
Developmental encoding has yet another advantage over genetic encoding, which is proving interesting to software engineers while simultaneously shedding light on the way living organisms develop: in the case of direct/genetic encoding, the length of the program grows proportionally to the complexity of the phenotype, which quickly makes the system unwieldy and again slows down its evolution. By comparison, indirect/developmental encoding means that a relatively small number of "instructions" can produce a variety of phenotypes, depending on the interactions among parts of the system and among these and the external environment. Complex phenotypes, then, can be evolved without the necessity to also evolve proportionally large genetic systems (Roggen et al. 2007). Looking at evolution through these lenses may also provide us with insights into one of the fundamental questions in biology: why did development evolved in the first place? As it turns out, when the phenotypes are simple, genetic and developmental encoding are roughly as efficient at evolving new solutions, because the genetic system is not too complicated. It is only when more complex phenotypes are favored that the advantage of indirect encoding becomes apparent (Roggen et al. 2007): perhaps this is why comparatively simpler life forms like bacteria do not need developmental encoding and better approximate the simple Genotype ${ }^{\circledR}$ Phenotype mapping assumed by the blueprint metaphor. But when evolution began to favor for whatever reason more complex, multicellular life forms, a new way of encoding information also evolved.

While much of the preceding discussion was framed in terms of the "problem of development," the second issue, which we referred to above as "the problem of environment" is actually conceptually analogous and can be thought of in a similar fashion. Biologists have known since immediately after the beginning of genetics, in 1900, that the same genotype often develops different phenotypes in different environments. This is difficult to make sense of if one thinks of genomes as a simple blueprint-like reservoir of information. Accordingly, this phenomenon - known as phenotypic plasticity (Pigliucci 2001) - has remained largely in the background of biological research for most of the 20th century.

During the last couple of decades, however, studies of phenotypic plasticity have taken center stage in evolutionary biology, ecology, and even molecular biology, because of the realization of the near-universality of the phenomenon. As usual, the initial approach to the study of the genetic basis of plasticity was guided by the blueprint metaphor, with researchers attempting to identify and map "genes for" plastic responses of a variety of phenotypes to a variety of environmental conditions. It quickly became clear, however, that plasticity is a 
complex developmental phenomenon, which requires a more nuanced approach and is no different, in principle, from the study of any other complex outcome of development. Indeed, if standard development can be thought of as the response of indirect/developmental encoding to the internal environment surrounding each cell, then plasticity can be seen as the similar response of indirect/developmental encoding to signals originating in the environment external to the organism (Jablonka 2007).

If the problem of environment is conceptually analogous to the problem of development, and both require a more sophisticated view of how organisms deploy genetic information, then we begin to see the possibility that the notion of genetic "information" itself is not quite so straightforward, and certainly is not one that fits comfortably with ideas like blueprints and machines. Accordingly, biologists and philosophers of science who have questioned the absolute centrality of genes inherent in the blueprint metaphor have proposed new ideas that represent some of the current frontiers of theoretical evolutionary biology. Let us briefly examine four of these, within the context of a broadened perspective of inheritance and evolution that is facilitated by moving away from blueprint-like thinking.

Mary Jane West-Eberhard (2003) has proposed that under certain circumstances genes may not be the initiators of evolutionary change, as the standard version of evolutionary theory maintains, but rather "followers." The standard model assumes that new heritable variation appears in a population of organisms because of either mutation or recombination, i.e. through genetic changes. This variation, if it has phenotypic outcomes that affect fitness, is then selected for or against by natural selection, and populations evolve. But according to the "genes as followers" model, sometime it is the external environment that changes first, catalyzing the appearance of a number of new phenotypes through already existing phenotypic plasticity. Should any of these phenotypes be adaptive, natural selection would then favor the appearance of any new combination of genes that happen to stabilize the plastic response. The crucial point is that under these circumstances (heritable) plasticity allows the population to survive in a novel environment without any genetic change. While in the long term evolution would still be a matter of gene-environment interactions mediated by natural selection (because genes would eventually mold and fine-tune the newly adaptive plastic response), at least some of the times the process would get started by an environment-induced developmental change, not by a genetic one. 
Eva Jablonka and Marion Lamb (2005) have gone in some sense a step further and attempted to formalize a broader view of evolutionary change, which depends on the existence of not one but four mechanisms of inheritance: first, the standard genetic system; second, a panoply of epigenetic heritable effects, based on recently or newly discovered phenomena, such as differential methylation of genes, alterations of chromatin structure, so-called interference RNAs, ${ }^{(7)}$ and changes in conformation of proteins (e.g., prions), to mention a few; third, behavioral inheritance, mediated through the ability of some animal species to mimic each other's behavior without having it to be "inscribed" in their genes; and fourth cultural inheritance, which is limited to humans and perhaps a few other species of primates, but which has had an obviously disproportionate effect on the recent history of our planet. Of course, it will be some time before theoretical population and quantitative genetics will be able to get a handle on the cumulative and interactive effects of the non-standard systems of inheritance, although work in that direction has already started (Johannes et al. 2008; Slatkin 2009).

A third unorthodox idea about inheritance has been developed by some evolutionary ecologists, and goes under the name of niche construction (Donohue et al. 2005; Laland and Sterelny 2006). The basic concept is that organisms do not experience their environment passively, but rather actively build their own niche at each generation. The textbook example of this is beavers building dams, which not only represent "artificial" environments for the beavers, but also affect the living of several other species in the local community. A crucial point about niche construction is that it is made possible by the fact that environmental materials and "information" are inherited along with the genes from one generation of beavers to the next. Without this "heritable" set of background conditions, the beaver genome simply could not enact the species-specific behavior of dam-building.

Finally, some philosophers of science have taken all of the above to suggest that we need to radically re-conceptualize the way we think of inheritance systems altogether. They articulated what is known as Developmental Systems Theory (Oyama et al. 2003), according to which genetic, epigenetic, behavioral, cultural and even environmental "information" is inherited in parallel and intricately interconnected fashion, creating cycles of causality which include the standard genetic mechanisms as just one of many necessary (and none individually sufficient) causes.

The preceding discussion, we argue, shows that the limitations intrinsic in metaphors such as "genes as blueprints" and the like are not just deleterious for science education — which 
would be bad enough. They actually misdirect or partially derail thinking about what sort of research programs biologists ought to carry out and how. While there is no question that the "molecular revolution" has been a central and positive development in biology, and indeed in science in general, throughout the second part of the 20th century, it is also becoming increasingly clear that the ultra-reductionist approach inspired and fueled by machineinformation metaphors is running out of steam and needs to be replaced with more sophisticated and realistic thinking (a kind of reasonable, or non-greedy reductionism, so to speak). Is it then time to retire metaphors like blueprints and machines, and to seek an alternative way to conceptualize biological organisms, or would it perhaps be better to abandon the use of metaphors in this field altogether?

The search for new metaphors

In their classic work on metaphors, Lakoff \& Johnson argue that the basic function of metaphorical concepts is to structure a new kind of experience in terms of a more familiar and delineated experience (Lakoff \& Johnson, 1980). In science as well as in everyday language, metaphors highlight particular aspects of whatever it is we are trying to grasp, but they will inevitably distort others. For example, the image of the 'tree of life,' with new species branching off as budding twigs and extinct species as dead branches, is an instructive approximation of the relations of evolutionary descent. However, it can also foster misconceptions about 'progress' in evolution, or lead to a simplistic conception of speciation events, or to a downplay of horizontal gene transfer and reticulate (i.e., by inter-species hybridization) speciation events. To give one more example, in physical chemistry the model of the atom as a miniature solar system, with electrons orbiting the nucleus as planets, though still having wide public appeal, is fundamentally inaccurate.

Of course, no metaphor will do its job perfectly, but it is crucial to realize, as Lakoff \& Johnson (1980) have shown, that the widespread deployment of a particular metaphor can have a feedback effect on the way we perceive things, not just how we present them to others. In the examples discussed in this paper, the lure of machine-information metaphors in the history of biology has invited scientists to think of genomes as 'blueprints' for organisms, written in the four-letter alphabet of DNA and readable in a manner analogous to a computer code. But as we 
have argued, the machine-information conception of living systems has led both the public and the scientific community astray.

In response to this problem, some scientists and science educators have proposed several alternative and improved metaphors to characterize the relationship between genotype and phenotype. Biologist Patrick Bateson, for instance, was probably the first to compare the DNA sequence of living organisms with a recipe for a cake (Dawkins \& Wong 2005, p. 414). The idea of a genetic recipe has several advantages over the blueprint metaphor, the most important being that it takes into account pleiotropy (one gene affecting more than one trait) and epistasis (genegene interactions), and that it is more sensitive to what we termed the problem of environment and the problem of development in the previous section. As a consequence, the simple picture of a one-to-one (or close to) correspondence between particular genes and phenotypic traits is abandoned, which becomes clear when one considers that there is no way to locate particular ingredients in individual crumbs of a cake (Dawkins, 1991, pp. 295-6). Accordingly, there is no possibility of reverse-engineering the end product to the set of procedures (the 'recipe') that made the final product possible. This has important consequences not just for science education, but for research agendas, as the idea of "reverse engineering" is commonly invoked everywhere from genomic studies to the understanding of the brain (though in the latter case in a different sense from the one used in molecular biology: Pinker 1997).

Of course, if carried too far, the recipe metaphor can in turn be quite misleading. To get the desired result, a cook has to lump together different ingredients in the correct proportions, and follow a set of instructions for handling the dough and preparing the oven. But as we saw, developmental encoding is an enormously more complex and very different sort of procedure, which is also highly dependent on epigenetic factors and unpredictable vagaries of the external environment. The expressions of specific genes in the course of development resembles nothing like the way a cook handles the ingredients of a recipe. Living organisms are also highly differentiated in a number of functional parts or components (cell types, tissues, etc.), in contrast with the homogenous cake that comes out of the oven. Moreover, the genome is not written in anything like a "language," as in the case of a recipe, and it certainly does not contain a description of the desired end product in any meaningful sense of the word "description."

Condit et al. have discussed the recipe metaphor as an alternative to talk of blueprints, pointing out that it was adopted "with surprising swiftness" by science popularizers and the media in the 1990s (Condit et al. 2002, p. 303). However, they also remark that, as a new 
"master metaphor" to capture the relationship between genotype and phenotype, the image of a recipe for a cake has little to recommend either. For example, evoking recipes can invite people to think of the genome as a step-by-step manual that describes "how to make a human," in that sense falling into the same trap as the idea of a blueprint.

That being said, if contrasted with the blueprint metaphor, the recipe metaphor conveys the point about lack of one-to-one correspondence between genes and phenotypes very well, and hence it highlights an important fact about development and the Genotype ® Phenotype map. If the recipe metaphor is used within this restricted context, for example in explicit contrast with the characteristics of a blueprint, it is immediately clear what are the salient points of connection with living systems, and people are less likely to be misled by stretching the metaphor beyond usefulness. If the recipe metaphor is presented as an alternative to the blueprint, however, it is bound to mislead people no less than its rival.

The same point applies to other interesting metaphors that have been proposed in this context, for example Lewis Wolpert's comparison of early embryonic development with the Japanese art of origami (Wolpert and Skinner, 1993; Dawkins \& Wong 2005). The analogy highlights the circuitous step-by-step development of the early embryo, ${ }^{(8)}$ but of course in a piece of origami art the structure is imposed top-down from an intelligent agent, whereas the functional differentiation in the embryo is regulated bottom-up by a complex interaction between genes and environment. Moreover, origami simply fold to yield the final product, which in a very real sense is already there from the beginning. This is definitely not the way embryos develop, with their ability to respond to local and external environmental fluctuations.

The general problem that we have been discussing seems to us to be not just that one kind of metaphor or another is woefully inadequate to conceptualize biological organisms and their evolution. It is that it simply does not seem to be possible to come up with a metaphor that is cogent and appropriate beyond a very limited conceptual space. Although some of the alternatives are more accurate than the blueprint metaphor (in some respects), we certainly have not found one that we would recommend as a replacement. Should we therefore try to avoid the use of metaphors in biological teaching and research altogether? Or do we simply expect too much from metaphors in science and education, and the best we can do is to use them more judiciously?

Conclusion: metaphors as teaching moments in scientific research and education 
Analogical and metaphorical thinking is widespread among human beings, although of course different cultures and historical moments inspire people to use different metaphors. After all, a metaphor is an attempt to make sense of novel concepts by pairing them with known ideas to increase our overall understanding. Metaphorical thinking is therefore part of our language, and language is inextricably connected to our thinking, but to put it as Wittgenstein did: "It is, in most cases, impossible to show an exact point where an analogy starts to mislead us" (Wittgenstein 1972, p. 28). Yet a great part of doing philosophy consists precisely in clarifying our language in an attempt to advance our thinking. To quote Wittgenstein (1951, § 109) again: "Philosophy is a battle against the bewitchment of our intelligence by means of our language." To complicate matters further, there is emerging empirical evidence that the human brain processes metaphors in a specific fashion: research on Alzheimer's patients, for instance (Amanzio et al. 2008), found that impairment of the brain's "executive" function, associated with the prefrontal cortex, leads to poor understanding of novel metaphors (while, interestingly, comprehension of familiar metaphors is unaffected). Metaphorical thinking seems to be a biologically entrenched functional mode of our brains, and may therefore be hard to avoid altogether.

Both science and philosophy have made ample use of metaphorical and analogical thinking, sometimes with spectacularly positive results, at other times more questionably so. Nonetheless, it seems that nowhere is metaphorical thinking so entrenched - and so potentially misleading - as in biology. Given the maturity of biology as a science, and considering that it deals with objects whose nature is not as alien to our daily experience as, say, those of quantum physics, we do not actually see any good reason for clinging on to outdated metaphors in biological education and research for characterizing living organisms, their genomes and their means of development. Taking into account the fact the machine/information metaphors have been grist to the mill of ID creationism, fostering design intuitions and other misconceptions about living systems, we think it is time to dispense with them altogether. Still, we are also not as naive as to expect that this advise will be followed by scientists and science educators any time soon, precisely because the machine/information metaphor is so entrenched in biology education. What to do then? We propose two approaches, one for science educators, the other for practicing scientists. 
In science education, talk of metaphorical thinking can be turned into a teaching moment. Students (and the public at large) would actually greatly benefit from explanations that contrast different metaphors with the express goal of highlighting the limitations intrinsic in metaphors and analogies. So, for instance, science educators and writers could talk about the human genome by introducing the blueprint metaphor, only to immediately point out why it does not capture much of what genomes and organisms are about; they could then proceed to familiarize their students and readers with alternative metaphors, say the recipe one, focusing on its differences with the original metaphor while of course not neglecting to point out the (different) deficiencies of the new approach as well. The goal of this process would be to foster a cautious attitude about metaphorical thinking, as well as to develop a broader understanding of how unlike commonsense modern science really is. On the latter point, it is interesting to note, for instance, that a popular refrain among evolution or global warming deniers is that "simple common sense" shows that the scientists are wrong, a position that ignores the proper weight of technical expertise in favor of a folk understanding of nature. It is therefore crucial that the public appreciates the limitations of common sense thinking about science.

There is an analogous teaching moment that can be brought to bear when research scientists engage in unbridled metaphorical thinking: we could refer to this as a philosophyappreciation moment. Scientists are notoriously insensitive to, or even downright dismissive of, considerations arising from the history and philosophy of their discipline, and often for good practical reasons: modern science is a highly specialized activity, where there is barely enough time to keep up with the overwhelming literature in one's own narrow field of research, and certainly not enough incentive to indulge in historical readings or philosophical speculation. Nonetheless, historians and philosophers of science can easily show the pitfalls of metaphorical thinking (by using well documented historical examples) and even get across to their colleagues some basic notions of philosophy (by analyzing the effects of particular metaphors on the development of specific lines of scientific inquiry). None of this will quickly amount to overcoming C.P. Snow's (1959) infamous divide between "the two cultures," but it may bring about better understanding and appreciation of philosophy by scientists, and perhaps even help science see new horizons that have been hitherto obscured by a superficially illuminating metaphor.

\section{Endnotes}


(1) See http://www.genome.gov/11006943

(2) Paley was not the first to pursue the analogy with a pocket watch. In fact, Paley borrowed the famous paragraph in the first chapter of his work from the book Regt gebruik der werelt beschouwingen (1715) by the Dutch physician Bernard Nieuwentijt, who was himself probably influenced by thinkers like William Derham, John Ray and Robert Boyle.

(3) Philo says that "it is a palpable and egregious partiality to confine our view entirely to that principle by which our own minds operate" (Hume 1998 [1779], p. 46).

(4) A survey by Condit et al. about the perception of the blueprint and recipe metaphor suggests that deeply religious people prefer the blueprint metaphor precisely because of its theistic connotations (Condit et al., 2002, p. 312).

(5) Thanks to xxx for this suggestion.

(6) See http://www.journeyinsidethecell.com/

(7) Methylation is a simple form of chemical alteration of DNA that affects gene expression; chromatin structure refers to alteration in the spatial distribution of the DNA-proteins ensemble that makes up chromosomes; interference RNAs (iRNAs) are small molecules of ribonucleic acid that also affect gene expression.

(8) See also the online video demonstration of origami embryology by Kathryn Tosney and Diana Darnell: http://origamiembryo.cba.arizona.edu/

\section{Literature Cited}

Alberts, B. (1998) The cell as a collection overview of protein machines: Preparing the next generation of molecular biologists. Cell 92, 291-294.

Amanzio, M., Geminiani, G., Leotta, D., and Cappa, S. (2008) Metaphor comprehension in Alzheimer's disease: Novelty matters. Brain and Language 107:1-10.

Aristotle (350BE/1991) De Anima. Prometheus Books.

Ashworth, W.B. (2003) Christianity and the Mechanistic Universe, in D.C. Lindberg and R.L. Numbers (eds.), When Science and Christianity Meet, pp. 61-84. University of Chicago Press.

Behe, M.J. (2006) Darwin's Black Box: The Biochemical Challenge to Evolution (10th Anniversary Edition). Simon and Schuster. 
Brown, T.L. (2003) Making Truth: Metaphor in Science. University of Illinois Press.

Ciliberti, S., Martin, O.C. and Wagner, A. (2007) Innovation and robustness in complex regulatory gene networks. Proceedings of the National Academy of Science USA 104:1359113596.

Condit, C.M., Bates, B.R., Galloway, R. et al. (2002) Recipes or blueprints for our genes? How contexts selectively activate the multiple meanings of metaphors. Quarterly Journal of Speech 88:303-25.

Davis, P.W., Kenyon, D.H., and Thaxton, C.B. (1993) Of Pandas and People: The Central Question of Biological Origins. Haughton Pub Co.

Dawkins, R. (1991) The Blind Watchmaker. Penguin books.

Dawkins, R. and Wong, Y. (2005) The Ancestor's Tale: A Pilgrimage to the Dawn of Life. Phoenix Press.

Darwin, C. (1859) On the Origin of Species. http://darwin-online.org.uk/

De Cruz, H. \& De Smedt, J. (2010) Science as Structured Imagination. Forthcoming in Journal of Creative Behavior.

Descartes, R. (1648/1972) Treatise of Man. Harvard University Press.

Donohue, K., Polisetty, C.R., and Wender, N.J. (2005) Genetic basis and consequences of niche construction: plasticity-induced genetic constraints on the evolution of seed dispersal in Arabidopsis thaliana. American Naturalist 165:537-50.

Fox Keller, E. (1995) Refiguring Life: Metaphors of Twentieth-Century Biology. Columbia University Press.

Hartmann, M., Haddow, P.C. and Lehre, P.K. (2007) The genotypic complexity of evolved faulttolerant and noise-robust circuits. Biosystems 87:224-232.

Hassoun, R., Schwartz, P., Feistel, K., Blum, M., and Viebahn, C. (2009) Axial differentiation and early gastrulation stages of the pig embryo. Differentiation: Aug 14 [Epub ahead of print].

Hendrikse, J.L., Parsons, T.E., and Hallgrímsson, B. (2007) Evolvability as the proper focus of evolutionary developmental biology. Evolution \& Development 9:393-401.

Hume, D. (1779/1998) Dialogues Concerning Natural Religion (2nd ed). Hackett.

Iimura, T., Denans, N., and Pourquié, O. (2009) Establishment of Hox vertebral identities in the embryonic spine precursors. Current Topics in Developmental Biology 88:201-34. 
Jablonka, E. (2007) The developmental construction of heredity. Developmental Psychobiology 49:808-17.

Jablonka, E. and Lamb, M.J. (2005) Evolution in Four Dimensions: Genetic, Epigenetic, Behavioral, and Symbolic Variation in the History of Life. MIT Press.

Jaroff, L. (1989) The Gene Hunt. Time, Mar. 20, pp. 62-67.

Johannes, F., Colot, V., and Jansen, R.C. (2008) Epigenome dynamics: a quantitative genetics perspective. Nature Review Genetics 9:883-890.

Kant, I. (2007/1790) Critique of Judgment. Cosimo Books.

Kaplan, J.M. and Pigliucci, M. (2001) Genes 'for' Phenotypes: A Modern History View. Biology and Philosophy 16:189-213.

Laland, K.N. and Sterelny, K. (2006) Perspective: seven reasons (not) to neglect niche construction. Evolution 60(9):1751-62.

Lakoff, G. and Johnson, M. (1980) Metaphors we live by. University of Chicago Press.

Levine, J.S. and Miller, K.R. (1994) Biology: Discovering Life. Heath Press.

Love, A.C. (2006) Evolutionary morphology and Evo-devo: hierarchy and novelty. Theory in Bioscience 124:317-33.

Martin, E. (1994) Flexible Bodies: Tracking Immunity in American Culture-from the Days of Polio to the Age of AIDS. Beacon Press.

Mayr, E. and Provine, W.B. (1998) The Evolutionary Synthesis. Harvard University Press.

Miller, K.R. (2000) Finding Darwin's God: A Scientist's Search for Common Ground Between God and Evolution. HarperCollins.

Miller, K.R. (2008) Only a Theory: Evolution and the Battle for America's Soul. Viking.

Minelli, A. and Fusco, G. (2005) Conserved versus innovative features in animal body organization. Journal of Experimental Zoology, B, Molecular Development and Evolution 304:520-5.

Müller, G.B. (2007) Evo-devo: extending the evolutionary synthesis. Nature Reviews Genetics 8:943-9.

Nelkin, D. (2001) Molecular metaphors: the gene in popular discourse. Nature Reviews Genetics 2:555-559.

Nieuwentyt, B. (1715) Het regt gebruik der werelt beschouwingen, ter overtuiginge van ongodisten en ongelovigen aangetoont. Wolters \& Pauli. 
Oyama, S., Griffiths, P.E. and Gray, R.D., eds. (2003) Cycles of Contingency: Developmental Systems and Evolution. MIT Press.

Paley, W. (1802) Natural Theology, or, Evidences of the Existence and Attributes of the Deity, Collected from the Appearances of Nature. Gould and Lincoln.

Pennock, R. T. (1999) Tower of Babel : the evidence against the new creationism, Bradford books. Cambridge (Mass.): MIT press.

Perakh, M. (2008) Flagella Myths. How Intelligent Design proponents created the myth that bacteria flagella look Like man-made machines. Skeptic 14:3.

Pinker, S. (1997) How the Mind Works. W.W. Norton.

Pigliucci, M. (2001) Phenotypic Plasticity: Beyond Nature and Nurture. Johns Hopkins University Press.

Pigliucci, M. (2002) Denying evolution : creationism, scientism, and the nature of science.

Sunderland, MA: Sinauer Associates.

Pigliucci, M. (2009) An extended synthesis for evolutionary biology. Annals of the New York Academy of Sciences 1168:218-28.

Roggen, D., Federici, D. and Floreano, D. (2007) Evolutionary morphogenesis for multi-cellular systems. Genetic Programs and Evolvable Machines 8:61-96.

Rutka, J.T., Kongkham, P., Northcott, P., Carlotti, C., Guduk, M., Osawa, H., Moreno, O., Seol, H.J., Restrepo, A., Weeks, A., Nagai, S., and Smith, C. (2009) The evolution and application of techniques in molecular biology to human brain tumors: a 25 year perspective. Journal of Neurooncology 92:261-73.

Saminathan, R., Pachiappan, A., Feng, L., Rowan, E.G., and Gopalakrishnakone, P. (2009)

Transcriptome profiling of neuronal model cell PC12 from rat pheochromocytoma. Cell and Molecular Neurobiology 29:533-48.

Schrödinger, E. (1944/1992) What is Life? Cambridge University Press.

Shanks, N. (2004) God, the Devil, and Darwin: A Critique of Intelligent Design Theory. Oxford University Press.

Shanks, N., and Joplin K. (1999) Redundant Complexity: A Critical Analysis of Intelligent Design in Biochemistry. Philosophy of Science 66:268-282.

Slatkin, M. (2009) Epigenetic inheritance and the missing heritability problem. Genetics 182:845-50.

Snow, C.P. (1959/1993) The Two Cultures. Cambridge University Press. 
Stanley, K.O. (2007) Compositional pattern producing networks: a novel abstraction of development. Genetics Programs and Evolvable Machines 8:131-162.

Sturm R.A. and Larsson, M. (2009) Genetics of human iris colour and patterns. Pigment Cell Melanoma Research 22:544-62.

Tian, C., Gregersen, P.K., and Seldin M.F. (2008) Accounting for ancestry: population substructure and genome-wide association studies. Human Molecular Genetics 17:R143-150.

Uttamchandani, M., Lu, C.H., and Yao, S.Q. (2009) Next generation chemical proteomic tools for rapid enzyme profiling. Accounts of Chemical Research 42:1183-92.

Young, M. (2004) Grand designs and facile analogies. Exposing Behe's mousetrap and Dembski's arrow. In M. Young and T. Edis (eds.), Why Intelligent Design Fails: A Scientific Critique of the New Creationism, pp. 20-31. Rutgers University Press.

Watson, J.D. and Crick, F.H. (1953) Molecular structure of nucleic acids; a structure for deoxyribose nucleic acid. Nature: 171:737-738.

West-Eberhard, M.J. (2003) Developmental Plasticity and Evolution. Oxford University Press.

Wittgenstein, L. (1951/2009) Philosophical Investigations. PMS Hacker and J. Schulte (Eds), Wiley.

Wittgenstein, L. (1972) The Blue and Brown Books. Preliminary Studies for the 'Philosophical Investigations'. Basil Blackwell.

Wolpert, L. and Skinner, D. (1993) The Triumph of the Embryo. Oxford University press.

Wu, Z. and Zhao, H. (2009) Statistical power of model selection strategies for genome-wide association studies. PLoS Genetics 5:e1000582. 